\title{
Cartilage tissue engineering for craniofacial reconstruction
}

\author{
Min-Sook Kim, Hyung-Kyu Kim, Deok-Woo Kim \\ Department of Plastic and Reconstructive Surgery, Korea University Ansan Hospital, Ansan, Korea
}

Severe cartilage defects and congenital anomalies affect millions of people and involve considerable medical expenses. Tissue engineering offers many advantages over conventional treatments, as therapy can be tailored to specific defects using abundant bioengineered resources. This article introduces the basic concepts of cartilage tissue engineering and reviews recent progress in the field, with a focus on craniofacial reconstruction and facial aesthetics. The basic concepts of tissue engineering consist of cells, scaffolds, and stimuli. Generally, the cartilage tissue engineering process includes the following steps: harvesting autologous chondrogenic cells, cell expansion, redifferentiation, in vitro incubation with a scaffold, and transfer to patients. Despite the promising prospects of cartilage tissue engineering, problems and challenges still exist due to certain limitations. The limited proliferation of chondrocytes and their tendency to dedifferentiate necessitate further developments in stem cell technology and chondrocyte molecular biology. Progress should be made in designing fully biocompatible scaffolds with a minimal immune response to regenerate tissue effectively.

\section{Keywords Cartilage / Tissue / Engineering / Chondrocyte / Stem cell}

\author{
Correspondence: Deok-Woo Kim \\ Department of Plastic and \\ Reconstructive Surgery, Korea \\ University Ansan Hospital, 123 \\ Jeokgeum-ro, Danwon-gu, \\ Ansan 15355, Korea \\ Tel: +82-31-412-5070 \\ Fax: +82-31-475-5074 \\ E-mail:deokwookim@gmail.com
}

This work was supported by the National Research Foundation of Korea (NRF) grant funded by the Korea government (MSIT) (No. 2020R1A2C1009216).

Received: June 23, $2020 \bullet$ Revised: July 14, $2020 \bullet$ Accepted: July 14, 2020

pISSN: 2234-6163 • elSSN: 2234-6171 • https://doi.org/10.5999/aps.2020.01095• Arch Plast Surg 2020;47:392-403

\section{INTRODUCTION}

Severe cartilage defects and congenital anomalies affect millions of people and involve considerable medical expenses. Tissue engineering offers many advantages over conventional treatments, as therapy can be tailored to specific defects using abundant bioengineered resources. Furthermore, as engineered tissue is theoretically immune-tolerant, immunosuppression is not required. Tissue engineering is increasingly studied and has been used in preclinical studies to reconstruct soft tissue, vessels, bones, and cartilage. This article introduces the basic concepts of cartilage tissue engineering and reviews progress in the field, with a focus on craniofacial reconstruction and facial aesthetics.

The craniofacial structure is highly individualized and of para- mount functional and aesthetic importance. However, craniofacial areas are frequently invaded by tumors and altered by trauma. Moreover, congenital malformations such as microtia require large amounts of autologous tissue for reconstruction. Craniofacial defects and anomalies have a serious impact on quality of life, and performing functional and aesthetically satisfactory reconstructions of facial structures are challenging. The standard treatment strategies are to replace the defects or damaged structures with autologous tissue [1-3]. However, the amount of donor bone, cartilage, skin, and soft tissue is restricted and their harvest can lead to significant morbidity. Tissues obtained from cadavers pose a risk of infection and immune response. Alloplastic materials have been developed to replace autologous cartilage grafts, but they frequently become exposed through 
the skin and cause infections. Thus, new strategies for craniofacial restoration need to be developed.

Facial cartilage tissues are present in the nose, ears, eyelids, and temporomandibular joint. They have a limited ability to regenerate, and defects or tears heal through fibrous scar tissue replacement. Conventional treatments for deformed or damaged cartilage are limited because of the scarcity of substitutable tissue, and aesthetic reconstructions of cartilaginous defects remain among the most challenging reconstructive surgical procedures. A highly representative example is external ear reconstruction, in which it is crucial to fabricate a patient-specific three-dimensional (3D) cartilage framework with natural skin coverage.

The basic concepts of tissue engineering consist of cells, scaffolds, and stimuli [4], although in some cases, cells are the only component required to form functional neocartilage [5]. Generally, the cartilage tissue engineering process includes the following steps: harvesting of autologous chondrogenic cells, cell expansion under a monolayer culture, redifferentiation under $3 \mathrm{D}$ culture, in vitro incubation with a scaffold, and transfer to patients (Fig. 1). Cartilage tissue engineering strategies can be categorized according to the types of scaffolds and grafted cells.

\section{MATERIALS IN CARTILAGE TISSUE ENGINEERING}

\section{Therapeutic cells}

Cells are the most important component of tissue engineering, and the cells commonly used in cartilage tissue engineering are listed in Table 1.

\section{Chondrocytes}

Chondrocytes are considered to be ideal candidate cells for cartilage tissue engineering. However, they have two disadvantages. First, it is necessary to harvest autologous cartilage to isolate

\section{Table 1. Cells used for cartilage tissue engineering}

\section{Chondrocytes}

Periosteum-derived progenitor cells

Mesenchymal stem cells

Bone marrow-derived

Adipose tissue-derived

Pluripotent stem cells

Embryonic stem cells

Induced pluripotent stem cells

\section{Fig. 1. Cartilage tissue engineering steps}

Cartilage tissue engineering steps: autologous chondrocyte harvest, cell expansion under two-dimensional (2D) culture, redifferentiation under three-dimensional (3D) culture, in vitro incubation with a scaffold, and transfer to patients.
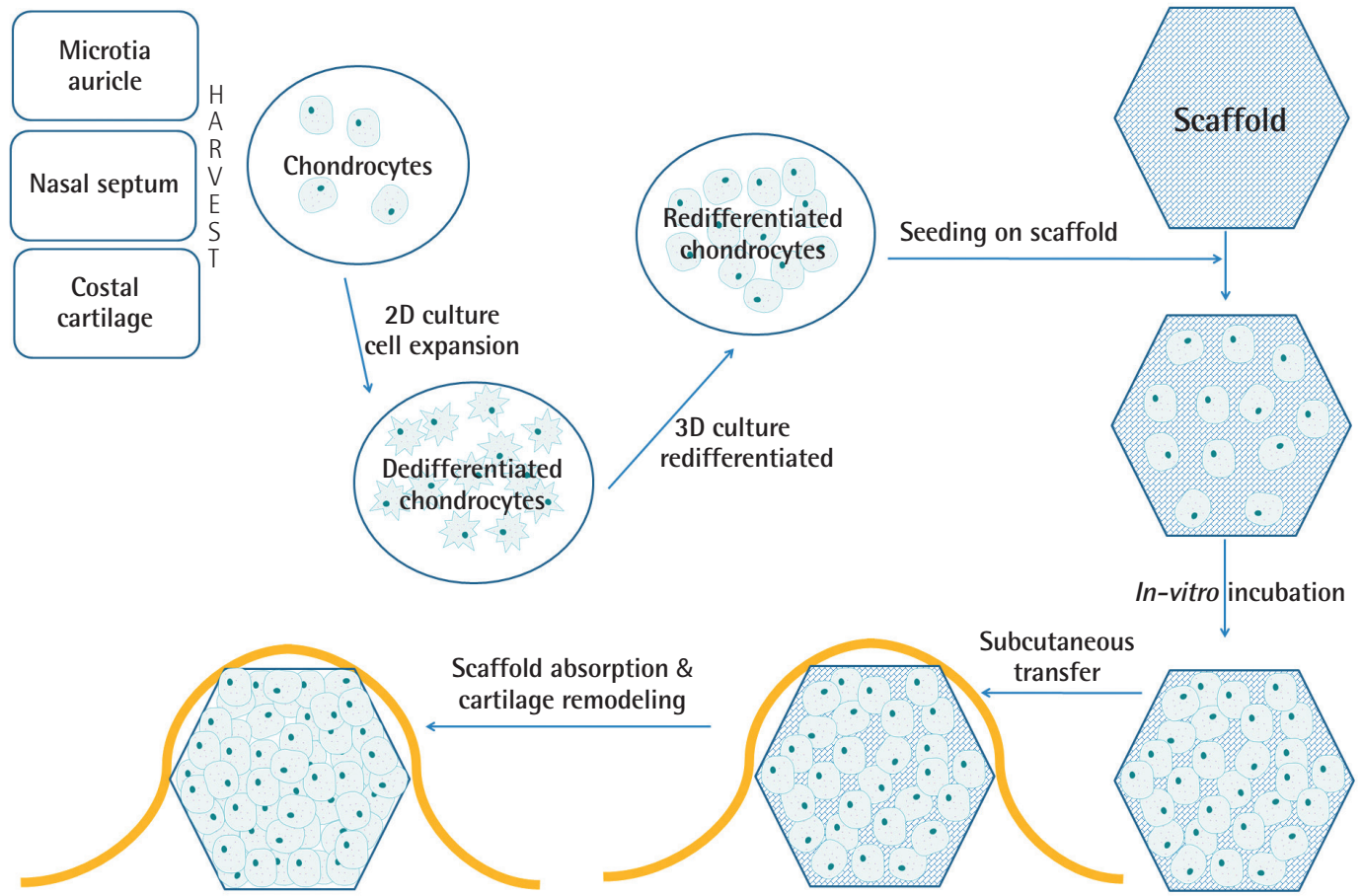

Subcutaneous

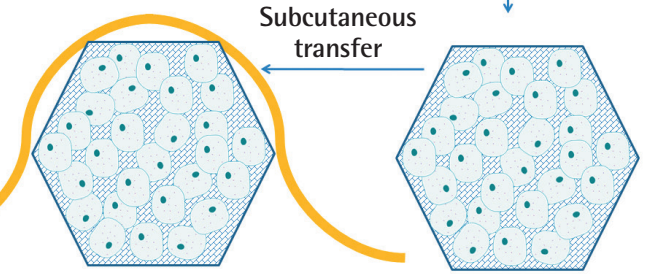


chondrocytes, which may result in scars and deformities. Second, chondrocytes have limited growth potential. After three monolayer culture passages, chondrocytes gradually lose their characteristics and show fibroblast-like features. The cells undergo dedifferentiation in subsequent passages. However, some research has shown that a hydrogel 3D culture system can achieve redifferentiation of dedifferentiated chondrocytes [6].

For chondrocyte isolation, the harvested cartilage tissue is cut into small pieces and digested overnight in collagenase type II at $37^{\circ} \mathrm{C}$. After digestion, the released cells are collected and cultured in growth medium to acquire a sufficient amount of cells for tissue engineering. The culture medium is then changed to a chondrogenic medium for hyaline-like cartilage formation. Recent clinical applications of tissue-engineered cartilage have mostly relied on chondrocyte-based tissue engineering.

\section{Mesenchymal stem cells}

Mesenchymal stem cells (MSCs) have several advantages in cartilage tissue engineering. MSCs can be isolated from various sources. Bone marrow-derived stem cells can be obtained by bone marrow aspiration and centrifugation. Adipose tissue-derived stem cells can be obtained from lipoaspirate or fatty tissues that would be discarded from various plastic surgery procedures. The fatty tissues are minced, digested with collagenase type I, and centrifuged. The pellets are resuspended, filtered through a $70-\mu \mathrm{m}$ mesh, and cultured in a $\mathrm{CO}_{2}$ incubator. Unlike chondrocytes, MSCs grow rapidly and maintain their characteristics for an extended time. Chondrogenic differentiation of MSCs requires a special medium containing several cytokines, such as bone morphogenetic protein (BMP)-2, tumor growth factor (TGF)- $\beta 1$, and TGF- $\beta 3$ [7].

Using MSCs for cartilage tissue engineering has some disadvantages. First, MSCs become senescent as sub-cultivation continues, and their capacity for chondrogenic differentiation decreases [8]. Another disadvantage is that MSC-induced chondrogenesis does not result in hyaline cartilage; instead, it produces type I collagen-rich fibrocartilage tissue [9]. However, for craniofacial reconstruction and aesthetic surgery, the fibrocartilaginous product can satisfy the requirements for structural support and graft durability. From this point of view, MSCs are more attractive for craniofacial tissue engineering than for articular cartilage tissue engineering.

\section{Pluripotent stem cells}

Embryonic stem cells

Embryonic stem cells (ESCs) have two distinctive characteristics: unlimited self-renewal and the ability to differentiate into almost all cell types. However, ethical problems are an issue im- peding the use of ESCs in tissue engineering [10].

Recent studies have reported chondrogenic differentiation of ESCs, attracting researchers' attention [11]. However, chondrogenic differentiation of ESCs requires complicated procedures, including embryoid body formation, micro-mass culture, and pellet culture [12]. Chondrogenic differentiation involves using a culture medium that includes various cytokines, such as insulin-like growth factor (IGF)-1, BMP-2, BMP-7, growth differentiation factor-5, TGF- $\beta 1$, and TGF- $\beta 3$ [12,13]. ESCs in hydrogel $3 \mathrm{D}$ culture have shown enhanced chondrogenic differentiation compared with those in monolayer culture [14].

Induced pluripotent stem cells

Somatic cells can be reprogrammed by forcing four transcription factors (Oct4, Sox2, c-Myc, and Klf4) to be expressed, thereby inducing pluripotent stem cells [15]. Induced pluripotent stem cells (iPSCs) also have a chondrogenic capacity under appropriate inducing conditions, and some studies have demonstrated cartilage formation in animal models [16,17]. Unlike ESCs, iPSCs are free from ethical concerns. However, iPSCs have a possible risk of tumorigenicity and safety problems related to the viral vector that is used for the introduction and expression of the four transcription factors [17].

\section{Scaffolds}

The roles of scaffolds in cartilage tissue engineering include providing structural support, enhancing chondrogenesis, and guiding the regeneration of cartilage. Scaffolds can be classified as natural and synthetic polymers. The ideal scaffold characteristics are biodegradability, biocompatibility, durability, low immunogenicity, cell adhesion, and ability to incorporate cells. The scaffolds commonly used in cartilage tissue engineering are listed in Table 2.

Table 2. Commonly used scaffolds for cartilage tissue engineering
Hydrogels
Collagen
Chitosan
Alginate
Hyaluronic acid
Decellularized extracellular matrix
Synthetic polyester
Polycaprolactone (PCL)
Polylactic acid (PLA)
Polyglycolic acid (PGA)
Hybrid or composite scaffolds
Scaffold-free strategies
Cell sheet engineering
Aggregate tissue engineering
Self-assembling process 


\section{Collagen}

Collagen has many ideal properties as a cartilage scaffold. It is biocompatible and biodegradable, and has low antigenicity. A collagen sponge facilitates the adhesion and proliferation of chondrocytes, and promotes secretion of fibrocartilage-like extracellular matrix (ECM) [18]. It has been proven that high levels of arginine, glycine, and aspartate residues in collagen increase cell attachment and differentiation $[19,20]$.

The chondrogenic differentiation of MSCs was found to be increased in collagen hydrogel, and a collagen type II hydrogel enhanced cell proliferation and chondrogenesis more than a collagen type I hydrogel [21].

A disadvantage of collagen scaffolds is their rapid degradation, which results in the loss of mechanical support before rigid cartilage formation. To overcome this disadvantage, highly crosslinked collagen scaffolds [22] and collagen-based composite scaffolds have been developed [23].

\section{Chitosan}

Chitosan has a similar chemical structure to the natural glycosaminoglycan that is the main component of the ECM in cartilage $[19,24]$. It is derived from chitin, which composes the exoskeleton of crustaceans [25]. Chondrocytes cultured on a chitosan sponge produced cartilage tissue [26], and chondrocytes grown in a chitosan-based hydrogel proliferated rapidly and formed hyaline cartilage tissues [27]. However, chitosan-based scaffolds have problems of fast degradation and poor mechanical properties. Crosslinking, Michael addition of amines, and composite scaffolds could improve the duration and mechanical properties of the scaffolds $[10,28]$.

\section{Alginate}

Alginate is a naturally formed polysaccharide extracted from brown sea algae [29]. Alginate is easily crosslinked using divalent ions, such as $\mathrm{Ca}^{2+}[30]$. Alginate porous sponges are broadly used in cartilage tissue engineering, and crosslinked alginate gels also have been researched as scaffolds for cartilage tissue engineering $[31,32]$. The addition of collagen type II to scaffolds has been found to yield increased cell proliferation and ECM production [33]. In recent years, alginate has been adopted for 3D bio-printing. A bio-ink based on an alginate-cellulose composite solution suspended with iPSCs and chondrocytes produced hyaline-like neocartilage [34]. Chondrocytes containing alginate and a collagen type I mixture was developed as a bioink and produced cartilage tissues [35].

\section{Hyaluronic acid}

Hyaluronic acid (HA) is an anionic polysaccharide that has been widely studied as a material for improving cartilage repair. HA, a major component of the ECM in cartilage, regulates the activity of chondrocytes through chondrocyte receptors (CD44, RHAMM) [36]. HA is capable of absorbing a large amount of water, to the point that HA hydrogel can have a water content exceeding 99.9\%. An HA hydrogel scaffold can provide a 3D water-rich environment for chondrocytes to proliferate, while maintaining their natural morphology [37]. Although HA crosslinking can prolong its duration, as in cosmetic fillers, crosslinking does not provide enough mechanical strength for crosslinked HA to be used in isolation to make a scaffold. To overcome this problem, composite scaffolds with polyurethane, polycaprolactone (PCL), and resveratrol have been studied [38-40].

\section{Decellularized extracellular matrix}

Cartilage ECM is composed of proteoglycans and collagen. The type of collagen is mainly type II in hyaline cartilage and a mixture of types I and II in fibrous cartilage [41]. Cartilage ECM is produced and maintained by chondrocytes, which compose only $1 \%$ to $5 \%$ of the total cartilage volume [42]. Decellularization can be performed through physical, chemical, and enzymatic methods. Physical decellularization uses freeze-thaw and osmotic pressure for cell lysis without significant disruption of the ECM. Chemical methods use acidic/basic conditions or detergents for decellularization. Enzymatic decellularization, using nucleases and proteases, is often performed directly after chemical decellularization to facilitate the removal of residual cellular material from the tissue [43].

Due to the dense ECM of cartilage, it is difficult to reseed cells into decellularized cartilage blocks. Various attempts have been reported, including making channels in full-thickness cartilage [44], pulverizing cartilage and packing it into molds [45], and using solubilized decellularized ECM as a hydrogel [46].

\section{Polyesters}

Polyesters are synthetic polymers that can easily be produced according to specific needs. However, synthetic polymers have relatively poor biological properties and cause foreign body reactions due to the release of bio-incompatible substances during degradation [19]. The polyester polymers most widely used for scaffolds are PCL, poly-L-lactic acid (PLLA), and polyglycolic acid (PGA). PCL has a relatively low melting point $\left(55^{\circ} \mathrm{C}-\right.$ $60^{\circ} \mathrm{C}$ ) and excellent blend-compatibility with different additives [47]. It has been used in absorbable plates and screws for fracture fixation in surgery. PCL is highly hydrophobic and has a longer degradation time than PLLA [19]. Its hydrophobic nature also leads to insufficient cell attachment and poor tissue integration [48]. PLLA, PGA, and PLA-PGA copolymer (PLGA) 
are widely used in cartilage tissue engineering because of their effectiveness as scaffolds and for chondrocyte delivery [19]. PLLA also has been used in plates and screws for fracture fixation, and PLGA has been used in absorbable surgical sutures. PLGA breaks down rapidly and releases substances that interfere with cartilage regeneration. A previous study found that PLLA was superior to PLGA in cartilage tissue engineering [49].

\section{Scaffold-free cartilage tissue engineering}

Scaffold-free cartilage tissue engineering mimics natural cartilage-forming processes, which include cell proliferation and differentiation, ECM production, and tissue maturation. Three distinct methods have been introduced: cell sheet engineering, aggregate engineering, and self-assembling [50].

\section{Cell sheet engineering}

This process resembles the appositional growth of natural cartilage from perichondrium, in which perichondrial cells (chondroblasts) proliferate and differentiate into chondrocytes layer by layer.

To make cell sheets, chondrocytes are expanded and cultured in a monolayer until they reach high confluence. When the cells produce sufficient ECM and form a discrete layer, the sheets are lifted from the cell culture plates [51]. The lifted cell sheets further undergo rolling, layering, or draping to form a durable thickness. Cell sheet engineering can produce neocartilage of clinically relevant dimensions and properties. However, several limitations should be solved. First, chondrocyte monolayer culture is frequently associated with dedifferentiation, in which chondrocytes gradually lose their characteristics [52]. Furthermore, external support structures are usually required to prevent cell sheet contraction [53]. The formation of a thick cartilage tissue requires extensive layering and limits diffusion to centrally located chondrocytes [50].

\section{Aggregate tissue engineering}

Rotational force is applied to cells in a suspension culture to produce cell aggregates [54]. There are two types of aggregate culture. Rotational culture uses slow rotation with a prolonged duration (60 rpm for several days to weeks). In contrast, pellet culture utilizes high-speed centrifugation for a few minutes to produce cell pellets from cell-suspended media. The merits of rotational culture include improved diffusion of nutrients and gas compared to static culture [55]. Aggregate culture can induce redifferentiation of chondrocytes that have expanded in monolayer culture [54]. When aggregates or pellets are formed and cartilage tissues are produced, chondrocytes proliferate minimally, except under specific culture conditions [55]. Carti- lage produced from aggregates has an uncontrolled shape and limited size. Fusing small aggregates to form larger pieces of cartilage with controlled shapes may be required for this technique to be viable for producing cartilage suitable for use in craniofacial reconstruction.

\section{Self-assembling process}

The self-assembling process consists of distinct phases that resemble embryonic cartilage development. A high-density cell suspension is applied onto a non-adherent mold of the desired shape, the cells become coalescent according to the differential adhesion hypothesis [56], cartilage ECM is produced, and functional tissue is formed as the matrix matures [57]. This technique has the advantage of producing cartilage with functional properties and a natural gross appearance [5]. However, the self-assembling process requires a high density of cells $\left(10^{7}\right.$ to $10^{8}$ cells $/ \mathrm{mL}$ ) in a mold [58]. To achieve such cell numbers, monolayer expansion with subsequent redifferentiation through $3 \mathrm{D}$ culture may be required [59].

\section{PROGRESS OF CARTILAGE TISSUE ENGINEERING FOR CRANIOFACIAL RECONSTRUCTION}

Trials for cartilage tissue engineering can be divided according to the cartilage type: articular cartilage or non-articular structural cartilage. For craniofacial reconstruction, nasal cartilage and ear cartilage are the main focuses of interest. Tissue engineering in plastic and reconstructive surgery aims to provide tissue for the reconstruction of congenital and acquired defects. Although many cartilage tissue engineering trials have focused on the reconstruction of articular cartilage, we review the progress of cartilage tissue engineering for craniofacial reconstruction.

\section{Nasal cartilage tissue engineering}

Nasal septal cartilage can be easily obtained by septoplasty and many trials have used it for cartilage tissue engineering. Nasal septal cartilage has the shape of a plane sheet and it is the most useful building block for rhinoplasty. However, in case of secondary rhinoplasty or a severely deformed nose, when the septal cartilage is unavailable, auricular concha cartilage or rib cartilage can be considered for harvesting. While autologous auricular and rib cartilage can be used as alternative graft sources in rhinoplasty, neither tissue satisfies the requirements for graft materials in rhinoplasty. Costal cartilage has the problem of warping, and auricular cartilage is not suitable for the struts of axial nasal structures. Due to its simple plate-like structure and versatile applications in reconstructive surgery and rhinoplasty, 
septal cartilage has become one of the most intriguing candidates for tissue engineering. The plate-shaped cartilage could be engineered in vitro without scaffolds [60] and implanted into immune-deficient animals [61].

A nasal dorsal graft has been made without a scaffold by injecting high-density cultured auricular chondrocytes into the patient's abdomen and using the resulting chondrofat tissues as dorsal grafts. Through the two-stage transplantation method, the authors successfully made a chondrofat composite tissue and reconstructed a deformed nose [62]. In another trial of nasal dorsal grafts, auricular chondrocytes were immersed in an atelocollagen gel and administered in porous PLLA scaffolds. The implant-shaped cell-containing scaffolds were implanted in the nasal dorsum to correct the deformed nasal shape [63].

The reconstruction of nasal alar defects with tissue-engineered cartilage was also successfully tried. Nasal alar defects following tumor resection surgery were reconstructed with tissue-engineered cartilage grafts and forehead flaps. The cartilage was engineered by culturing autogenous septal chondrocytes on collagen bilayer sheets for 4 weeks. The reconstructed noses showed good results, both aesthetically and functionally [64].

In recent trials, polyester scaffolds have frequently been used in combination with $3 \mathrm{D}$ printing. There are two main methods: a 3D printer either directly prints scaffolds or makes negative molds that compress scaffolds. In a study, composite scaffolds were 3D-printed by layer-by-layer deposition of PCL and chondrocyte-containing alginate gel. The PCL layers provided mechanical support and the cell-laden alginate gel was intended to develop neocartilage. The constructs were cultured in vitro and grafted in nude mice, and chondrogenesis was demonstrated in the chondrocyte-laden alginate gel layer [65]. In the latter method, the negative molds compressed PGA fibers that resembled a cotton ball, and the compressed PGA structure was treated with PLLA for solidification. Cadaveric alar cartilage was scanned using computed tomography and 3D-reconstructed, and the 3D images were then converted into images of the negative molds. The negative molds were printed with the $3 \mathrm{D}$ printer, and the PGA fibers were compressed as described above. The resulting ala-shaped PGA/PLLA scaffolds were infiltrated with nasal septal chondrocytes and incubated for 4 weeks. The constructs were implanted into nude mice, and resulted in neocartilage formation with an anatomical alar shape [66].

Chondrocytes have a limited proliferation capacity and a tendency to dedifferentiate. To overcome the limitations of this cell population, mixed MSCs and chondrocytes were used for cartilage tissue engineering. MSCs and chondrocytes (at an 8:2 ratio) were mixed with bio-ink made from cellulose and alginate. The 3D-printed constructs were then implanted in athymic mice. The resulting cartilage demonstrated a boosting effect of MSCs on chondrocyte proliferation [67].

\section{Table 3. Trials of tissue engineering of human nasal cartilage}

\begin{tabular}{|c|c|c|c|c|}
\hline Author (year) & Cells & Scaffolds & Culture/graft condition & Results \\
\hline Alexander et al. (2010) [60] & $\begin{array}{l}\text { Nasal septal chondrocytes, } \\
\text { alginate-recovered }\end{array}$ & Scaffold-free, self-assembly & $\begin{array}{l}2 \% \text { human serum, IGF-1, } \\
\text { GDF-5 }\end{array}$ & Rigid 1.7-mm-thick hyaline cartilage plate \\
\hline Chang et al. (2012) [61] & $\begin{array}{l}\text { Nasal septal chondrocytes, } \\
\text { alginate-recovered }\end{array}$ & Scaffold-free, self-assembly & $\begin{array}{l}\text { In vitro culture for } 5 \text { weeks } \\
\text { Implantation in nude mice }\end{array}$ & Rigid 0.5-mm-thick hyaline cartilage plate \\
\hline Yanaga et al. (2013) [62] & $\begin{array}{l}\text { Ear concha chondrocytes, } \\
\text { redifferentiated by multilayering }\end{array}$ & Scaffold-free & Injection into human abdomen & $\begin{array}{l}\text { Chondrofat tissue suitable for nasal dorsum } \\
\text { and chin augmentation }\end{array}$ \\
\hline Fulco et al. (2014) [64] & Nasal septal chondrocytes & Collagen sheets (Chondro-Gide) & Graft to nasal alar defects & $\begin{array}{l}\text { Chondrogenesis was confirmed after } \\
6 \text { months }\end{array}$ \\
\hline Xu et al. (2015) [66] & Nasal septal chondrocytes & $\begin{array}{l}\text { PGA fiber compressed in } \\
\text { 3D-printed negative mods and } \\
\text { treated with PLLA }\end{array}$ & $\begin{array}{l}\text { In vitro culture for } 4 \text { weeks } \\
\text { Implantation in nude mice }\end{array}$ & Alar shaped cartilage formation in vivo \\
\hline Schwarz et al. (2015) [67] & Nasal septal chondrocytes & $\begin{array}{l}\text { Chondrocyte culture on a porcine } \\
\text { decellularized septal cartilage }\end{array}$ & $\begin{array}{l}\text { Chondrocyte differentiation } \\
\text { medium }\end{array}$ & Chondrocyte infiltration and GAG synthesis \\
\hline Kundu et al. (2015) [65] & Nasal septal chondrocytes & $\begin{array}{l}\text { 3D printing with } P C L \text { and } \\
\text { alginate-interlaced composite }\end{array}$ & Implantation in nude mice & Chondrogenesis in alginate layer \\
\hline Akbari et al. (2016) [69] & $\begin{array}{l}\text { Nasal septal chondrocytes, } \\
\text { redifferentiated by multilayering }\end{array}$ & Scaffold-free & Dynamic rotational bioreactor & $\begin{array}{l}\text { Mechanically stable } 0.9 \text {-mm-thick } \\
\text { cylindrical cartilage }\end{array}$ \\
\hline Apelgren et al. (2017) [67] & $\begin{array}{l}\text { Nasal septal chondrocytes and } \\
\text { BMSCs }\end{array}$ & $\begin{array}{l}\text { 3D printed cellulose and alginate } \\
\text { hydrogel }\end{array}$ & Nude mice & $\begin{array}{l}\text { Cartilage formation } \\
\text { MSCs enhanced chondrocyte proliferation }\end{array}$ \\
\hline Hoshi et al. (2017) [63] & Auricular chondrocytes & $\begin{array}{l}\text { Atelocollagen gel in porous PLLA } \\
\text { structures }\end{array}$ & Nasal dorsal graft & MRI findings: intact grafts after 1 year \\
\hline
\end{tabular}


The progress of human nasal cartilage tissue engineering is summarized in Table 3 [60-69].

\section{Auricular cartilage tissue engineering}

Auricular cartilage tissue engineering has a history of more than 20 years. The first trial with human chondrocytes was published in 1999, and the basic concept of PGA fiber scaffolds has continued in current trials. In the original study, chondrocytes were obtained from pediatric auricular cartilage, and were seeded on a 1-cm PGA fiber mesh. The cell-laden PGA fiber scaffolds were incubated in vitro for several weeks and implanted in nude mice. The resultant neocartilage showed the histological features of natural cartilage [70].

Cotton-like PGA fiber scaffolds underwent further development by immersion in 2\% PLLA dissolved in methylene chloride. The PLLA functioned to enhance the rigidity and crosslinking of the PGA fibers. The resultant neocartilage showed equivalent mechanical strength to that of native cartilage [71].

The cartilage-forming capacity of chondrocytes from auricles affected by microtia was compared to that of chondrocytes from normal auricles, and it was concluded that there were no significant differences $[72,73]$.

The first clinical trial of microtia reconstruction with tissueengineered cartilage was conducted by Yanaga et al. [74] and published in 2009. Chondrocytes from patients with microtia were expanded in a dedifferentiated state, and redifferentiated by a chondrocyte multilayering method. The final gelatinousformed cells $\left(0.5-1 \times 10^{7}\right.$ cells $/ \mathrm{mL} ; 10$ to $\left.50 \mathrm{~mL}\right)$ were injected into patients' lower abdomen. Six months later, a solid newly generated cartilage block had formed, and was surgically harvested. The cartilage blocks were used for auricular cartilage frameworks. Long-term results (up to 5 years) demonstrated good convolutions without clear cartilage resorption, equivalent to those of traditional costal cartilage embedding and elevation procedures [75].

Chondrocytes have a limited ability to proliferate, and harvesting the source cartilage poses a risk of complications. Several trials showed that a mixture of auricular chondrocytes and MSCs yielded cartilage that was equivalent to constructs made from solely chondrocytes. The ratio of chondrocytes and MSCs varied from $1: 1$ to $1: 3[76,77]$.

A recent clinical trial of microtia reconstruction with tissueengineered cartilage was published in 2018 [78]. 3D convolutions and the shape of the cartilage framework were created by $3 \mathrm{D}$ printing technology. The compressing forces of the skin envelope, which may deform the convolutions of grafted tissueengineered neocartilage, could be endured by a sandwich structure containing rigid PCL struts. The scaffolds were composed of a PGA fiber mesh coated with PLLA. The opposite normal ear was scanned and 3D-reconstructed. Negative molds of the ear framework were made using 3D printing technology. A grid of PCL struts was sandwiched between two PGA fiber meshes. The sandwich structures were compressed by two negative molds that had the shape of the anatomical ear. The resultant ear frameworks were then soaked in PLLA solution for crosslinking. Chondrocytes from patients with microtia were expanded and seeded on the ear scaffolds. The cell-laden scaffolds were further cultivated in serum-free chondrogenic medium for 12 weeks. The final tissue-engineered neocartilage was embedded beneath the pre-expanded mastoid skin. The reconstructed external ear maintained its shape up to 2 years. The progress of human auricular cartilage tissue engineering is summarized in Table 4 [70-79].

\section{PROBLEMS TO BE SOLVED}

Despite the promising prospects of cartilage tissue engineering, some problems and challenges still exist due to current limitations.

A problem facing cartilage tissue engineering is that many cells are needed to make sufficient neocartilage, since chondrocytes have a low proliferation rate and a tendency to dedifferentiate. Efforts have been made to address these issues, including redifferentiation of chondrocytes in 3D culture systems, the use of adult stem cells, and the use of growth factors to promote chondrocyte proliferation and redifferentiation [80]. Some growth factors that have been used to promote neocartilage formation include TGF- $\beta 1$, TGF- $\beta 2$, TGF- $\beta 3$, platelet-derived growth factor subunit b, BMP-2, BMP-6, BMP-7, IGF-1, and fibroblast growth factor-2 [74,81-86]. However, further understanding of various growth factors and their effects on chondrocytes are required to popularize the use of tissue-engineered cartilage in craniofacial reconstruction procedures. Another solution to compensate for the large number of chondrocytes relies on development of stem cell technology. Stem cells theoretically have an unlimited proliferation capacity. Although adult stem cells are mortal and become senescent, they can be easily obtained. Pluripotent stem cells can differentiate into chondrocytes, but the procedures are complex and involve various ethical and safety problems. The use of MSCs can alleviate such problems, but the regenerated cartilage has extensive fibrous components. In recent trials, mixtures of MSCs and chondrocytes regenerated histologically appropriate cartilage [76,77].

3D modeling and printing technologies, which can be used to tailor patient-specific scaffolds, have become popular in cartilage tissue engineering. However, current technologies are limit- 
Table 4. Trials of tissue engineering of human auricular cartilage

\begin{tabular}{|c|c|c|c|c|}
\hline Author (year) & Cells & Scaffolds & Culture/graft condition & Results \\
\hline Rodriguez et al. (1999) [70] & Pediatric auricular chondrocytes & PGA fiber mesh & $\begin{array}{l}\text { In vitro culture for several weeks } \\
\text { Implantation in nude mice }\end{array}$ & Neocartilage formation \\
\hline Kamil et al. (2004) [72] & $\begin{array}{l}\text { Microtia chondrocytes } \\
\text { Normal auricular chondrocytes }\end{array}$ & Pluronic F-127 hydrogel & Injected into nude mice & $\begin{array}{l}\text { Neocartilage comparable from both } \\
\text { normal and microtia chondrocytes }\end{array}$ \\
\hline Park et al. (2004) [71] & Auricular chondrocytes & PGA fiber mesh coated with PLLA & $\begin{array}{l}\text { In vitro culture for } 4 \text { days } \\
\text { Implantation in nude mice }\end{array}$ & $\begin{array}{l}\text { Durable neocartilage comparable to } \\
\text { native cartilage }\end{array}$ \\
\hline $\begin{array}{l}\text { Yanaga et al. }(2009,2012) \\
{[74,75]}\end{array}$ & $\begin{array}{l}\text { Microtia chondrocytes, } \\
\text { redifferentiated by multilayering }\end{array}$ & Scaffold-free & $\begin{array}{l}\text { Injection into human abdomen } \\
\text { Framework insertion into } \\
\text { subcutaneous pocket }\end{array}$ & $\begin{array}{l}\text { Formation of cartilage block } \\
\text { Ear frameworks maintained up to } 6 \\
\text { years }\end{array}$ \\
\hline Zhang et al. (2014) [76] & $\begin{array}{l}\text { Microtia chondrocytes } \\
\text { BMSCs (1:3) }\end{array}$ & $\begin{array}{l}\text { Pressed PGA fiber mesh coated } \\
\text { with PLA }\end{array}$ & $\begin{array}{l}\text { In vitro culture for } 1 \text { week } \\
\text { Implantation in nude mice }\end{array}$ & $\begin{array}{l}\text { Neocartilage formation comparable } \\
\text { to that from } 100 \% \text { chondrocytes }\end{array}$ \\
\hline Nakao et al. (2017) [73] & $\begin{array}{l}\text { Microtia chondrocytes } \\
\text { Normal auricular chondrocytes }\end{array}$ & PGA fiber mesh & $\begin{array}{l}\text { Culture in chondrogenic medium } \\
\text { for } 7 \text { days } \\
\text { Implantation in nude mice }\end{array}$ & Elastic neocartilage formation \\
\hline Zhou et al. (2018) [78] & Microtia chondrocytes & $\begin{array}{l}\text { PCL strut sandwiched between } \\
\text { PGA mesh, pressed by } \\
\text { 3D-printed ear molds, coated } \\
\text { with PLLA }\end{array}$ & $\begin{array}{l}\text { Culture in serum-free chondrogenic } \\
\text { medium for } 12 \text { weeks } \\
\text { Framework insertion into } \\
\text { subcutaneous pocket }\end{array}$ & $\begin{array}{l}\text { Chondrogenesis confirmed by } \\
\text { histology } \\
\text { External ear structure maintained up } \\
\text { to } 2 \text { years }\end{array}$ \\
\hline Cohen et al. (2018) [77] & $\begin{array}{l}\text { Auricular chondrocytes } \\
\text { MSCs (1:1) }\end{array}$ & Collagen gel & Implantation in nude mice & $\begin{array}{l}\text { The mixed cells generated cartilage } \\
\text { equivalent to constructs containing } \\
\text { solely chondrocytes }\end{array}$ \\
\hline Bernstein et al. (2018) [79] & $\begin{array}{l}\text { Auricular chondrocytes at } \\
\text { passages } 3,4 \text {, and } 5\end{array}$ & Collagen gel & Implantation in nude mice & $\begin{array}{l}\text { Late-passage cells formed elastic } \\
\text { cartilage that was similar to native } \\
\text { cartilage }\end{array}$ \\
\hline
\end{tabular}

ed in manufacturing biocompatible porous scaffolds with durable mechanical strength. A recent clinical trial adopted 3D printing technologies to fabricate patient-specific auricular scaffolds [78]. However, they did not directly print 3D scaffolds, but instead printed negative molds for compressing PGA fiber meshes. The bio-printing technologies used a mixture of chondrocytes and hydrogel as a bio-ink, and the resulting constructs regenerated cartilage structures when implanted into immunedeficient mice [67]. However, the hydrogel scaffolds could not sustain their shape during chondrogenesis. Bio-ink and PCL interlace printing have been tried to make a durable structure with chondrogenicity [65], but the stability of the structure after the degradation of PCL has not been demonstrated. Future developments of 3D printing technologies will make it possible to print more durable, tissue-incorporable, and biocompatible scaffolds for cartilage tissue engineering.

The immune reaction and degradation of scaffolds are another problem in cartilage tissue engineering. Scaffold degradation may elicit inflammation, which compromises tissue healing and regeneration [87]. Scaffolds usually elicit an immune response and cause foreign body reactions as a result of their biological, chemical, and physical properties [88]. PLGA, which is widely used in cartilage tissue engineering, degrades into glycolic acid and lactic acid. The degradation products of PLGA reduce the $\mathrm{pH}$ in the surrounding tissue, cause inflammation, and inhibit collagen production [89]. In recent years, studies on biomaterials for scaffolds have focused on the immune response and degradation profile, as many researchers have come to recognize the close relationship of the inflammatory reaction with tissue regeneration outcomes [87]. To regenerate tissue effectively, progress should be made in designing fully biocompatible scaffolds that have a minimal immune response. Furthermore, the speed of scaffold degradation should keep pace with that of cartilage regeneration.

\section{NOTES}

\section{Conflict of interest}

No potential conflict of interest relevant to this article was reported.

\section{Author contribution}

Data curation: MS Kim, HK Kim. Formal analysis: MS Kim, HK Kim. Writing - original draft: DW Kim. Writing - review \& editing: DW Kim. 


\section{ORCID}

Min-Sook Kim

https://orcid.org/0000-0002-8601-9049

Hyung-Kyu Kim

https://orcid.org/0000-0002-7987-5314

Deok-Woo Kim

\section{REFERENCES}

1. Rojdmark J, Cheema M. Design of a combined cartilage graft crusher, morselizer and holder for use in rhinoplasty. Arch Plast Surg 2019;46:282-4.

2. Baek S, Chung JH, Yoon ES, et al. Algorithm for the management of ectropion through medial and lateral canthopexy. Arch Plast Surg 2018;45:525-33.

3. Jeong HH, Choi DH, Hong JP, et al. Use of a helical composite free flap for alar defect reconstruction with a supermicrosurgical technique. Arch Plast Surg 2018;45:466-9.

4. Lavernia L, Brown WE, Wong BJF, et al. Toward tissue-engineering of nasal cartilages. Acta Biomater 2019;88:42-56.

5. DuRaine GD, Brown WE, Hu JC, et al. Emergence of scaffold-free approaches for tissue engineering musculoskeletal cartilages. Ann Biomed Eng 2015;43:543-54.

6. Caron MM, Emans PJ, Coolsen MM, et al. Redifferentiation of dedifferentiated human articular chondrocytes: comparison of $2 \mathrm{D}$ and $3 \mathrm{D}$ cultures. Osteoarthritis Cartilage 2012;20:1170-8.

7. Murphy MK, Huey DJ, Hu JC, et al. TGF- $\beta 1$, GDF-5, and BMP-2 stimulation induces chondrogenesis in expanded human articular chondrocytes and marrow-derived stromal cells. Stem Cells 2015;33:762-73.

8. Beane OS, Darling EM. Isolation, characterization, and differentiation of stem cells for cartilage regeneration. Ann Biomed Eng 2012;40:2079-97.

9. Tan AR, Hung CT. Concise review: mesenchymal stem cells for functional cartilage tissue engineering: taking cues from chondrocyte-based constructs. Stem Cells Transl Med 2017;6:1295-303.

10. Zhao Z, Fan C, Chen F, et al. Progress in articular cartilage tissue engineering: a review on therapeutic cells and macromolecular scaffolds. Macromol Biosci 2020;20:e1900278.

11. Nakayama N, Pothiawala A, Lee JY, et al. Human pluripotent stem cell-derived chondroprogenitors for cartilage tissue engineering. Cell Mol Life Sci 2020;77:2543-63.

12. Suchorska WM, Augustyniak E, Richter M, et al. Modified methods for efficiently differentiating human embryonic stem cells into chondrocyte-like cells. Postepy Hig Med Dosw (Online) 2017;71:500-9.

13. Toh WS, Lee EH, Guo XM, et al. Cartilage repair using hyaluronan hydrogel-encapsulated human embryonic stem

cell-derived chondrogenic cells. Biomaterials 2010;31:696880.

14. Hwang NS, Varghese S, Elisseeff J. Cartilage tissue engineering: directed differentiation of embryonic stem cells in threedimensional hydrogel culture. Methods Mol Biol 2007; 407:351-73.

15. Takahashi K, Yamanaka S. Induction of pluripotent stem cells from mouse embryonic and adult fibroblast cultures by defined factors. Cell 2006;126:663-76.

16. Ko JY, Kim KI, Park S, et al. In vitro chondrogenesis and in vivo repair of osteochondral defect with human induced pluripotent stem cells. Biomaterials 2014;35:3571-81.

17. Phillips MD, Kuznetsov SA, Cherman N, et al. Directed differentiation of human induced pluripotent stem cells toward bone and cartilage: in vitro versus in vivo assays. Stem Cells Transl Med 2014;3:867-78.

18. Warth RJ, Rodkey WG. Resorbable collagen scaffolds for the treatment of meniscus defects: a systematic review. Arthroscopy 2015;31:927-41.

19. Del Bakhshayesh AR, Asadi N, Alihemmati A, et al. An overview of advanced biocompatible and biomimetic materials for creation of replacement structures in the musculoskeletal systems: focusing on cartilage tissue engineering. J Biol Eng 2019; 13:85.

20. Arakawa C, Ng R, Tan S, et al. Photopolymerizable chitosan-collagen hydrogels for bone tissue engineering. J Tissue Eng Regen Med 2017;11:164-74.

21. Yang K, Sun J, Wei D, et al. Photo-crosslinked mono-component type II collagen hydrogel as a matrix to induce chondrogenic differentiation of bone marrow mesenchymal stem cells. J Mater Chem B 2017;5:8707-18.

22. Omobono MA, Zhao X, Furlong MA, et al. Enhancing the stiffness of collagen hydrogels for delivery of encapsulated chondrocytes to articular lesions for cartilage regeneration. J Biomed Mater Res A 2015;103:1332-8.

23. Wang J, Yang $\mathrm{Q}_{2}$ Cheng N, et al. Collagen/silk fibroin composite scaffold incorporated with PLGA microsphere for cartilage repair. Mater Sci Eng C Mater Biol Appl 2016;61: 705-11.

24. Hu Y, Chen J, Fan T, et al. Biomimetic mineralized hierarchical hybrid scaffolds based on in situ synthesis of nano-hydroxyapatite/chitosan/chondroitin sulfate/hyaluronic acid for bone tissue engineering. Colloids Surf B Biointerfaces 2017;157:93-100.

25. Younes I, Rinaudo M. Chitin and chitosan preparation from marine sources: structure, properties and applications. Mar Drugs 2015;13:1133-74.

26. Nettles DL, Elder SH, Gilbert JA. Potential use of chitosan 
as a cell scaffold material for cartilage tissue engineering. Tissue Eng 2002;8:1009-16.

27. Ladet SG, Tahiri K, Montembault AS, et al. Multi-membrane chitosan hydrogels as chondrocytic cell bioreactors. Biomaterials 2011;32:5354-64.

28. Zhao P, Deng C, Xu H, et al. Fabrication of photo-crosslinked chitosan- gelatin scaffold in sodium alginate hydrogel for chondrocyte culture. Biomed Mater Eng 2014;24:63341.

29. Hecht H, Srebnik S. Structural characterization of sodium alginate and calcium alginate. Biomacromolecules 2016;17: 2160-7.

30. Patel MA, AbouGhaly MH, Schryer-Praga JV, et al. The effect of ionotropic gelation residence time on alginate crosslinking and properties. Carbohydr Polym 2017;155:362-71.

31. Miralles G, Baudoin R, Dumas D, et al. Sodium alginate sponges with or without sodium hyaluronate: in vitro engineering of cartilage. J Biomed Mater Res 2001;57:268-78.

32. Ewa-Choy YW, Pingguan-Murphy B, Abdul-Ghani NA, et al. Effect of alginate concentration on chondrogenesis of cocultured human adipose-derived stem cells and nasal chondrocytes: a biological study. Biomater Res 2017;21:19.

33. Almeida HV, Sathy BN, Dudurych I, et al. Anisotropic shape-memory alginate scaffolds functionalized with either type I or type II collagen for cartilage tissue engineering. Tissue Eng Part A 2017;23:55-68.

34. Nguyen D, Hagg DA, Forsman A, et al. Cartilage tissue engineering by the $3 \mathrm{D}$ bioprinting of iPS cells in a nanocellulose/alginate bioink. Sci Rep 2017;7:658.

35. Yang X, Lu Z, Wu H, et al. Collagen-alginate as bioink for three-dimensional (3D) cell printing based cartilage tissue engineering. Mater Sci Eng C Mater Biol Appl 2018;83:195201.

36. Salwowska NM, Bebenek KA, Zadlo DA, et al. Physiochemical properties and application of hyaluronic acid: a systematic review. J Cosmet Dermatol 2016;15:520-6.

37. Dvorakova J, Kucera L, Kucera J, et al. Chondrogenic differentiation of mesenchymal stem cells in a hydrogel system based on an enzymatically crosslinked tyramine derivative of hyaluronan. J Biomed Mater Res A 2014;102:3523-30.

38. Mintz BR, Cooper JA Jr. Hybrid hyaluronic acid hydrogel/ poly( $\varepsilon$-caprolactone) scaffold provides mechanically favorable platform for cartilage tissue engineering studies. $\mathrm{J}$ Biomed Mater Res A 2014;102:2918-26.

39. Sheu SY, Chen WS, Sun JS, et al. Biological characterization of oxidized hyaluronic acid/resveratrol hydrogel for cartilage tissue engineering. J Biomed Mater Res A 2013;101: 3457-66.
40. Hung KC, Tseng CS, Dai LG, et al. Water-based polyurethane $3 \mathrm{D}$ printed scaffolds with controlled release function for customized cartilage tissue engineering. Biomaterials 2016;83:156-68.

41. Chen JL, Duan L, Zhu W, et al. Extracellular matrix production in vitro in cartilage tissue engineering. J Transl Med 2014;12:88.

42. Akkiraju $\mathrm{H}$, Nohe A. Role of chondrocytes in cartilage formation, progression of osteoarthritis and cartilage regeneration. J Dev Biol 2015;3:177-92.

43. Kim YS, Majid M, Melchiorri AJ, et al. Applications of decellularized extracellular matrix in bone and cartilage tissue engineering. Bioeng Transl Med 2018;4:83-95.

44. Luo L, Eswaramoorthy R, Mulhall KJ, et al. Decellularization of porcine articular cartilage explants and their subsequent repopulation with human chondroprogenitor cells. J Mech Behav Biomed Mater 2015;55:21-31.

45. Gawlitta D, Benders KE, Visser J, et al. Decellularized cartilage-derived matrix as substrate for endochondral bone regeneration. Tissue Eng Part A 2015;21:694-703.

46. Rothrauff BB, Yang G, Tuan RS. Tissue-specific bioactivity of soluble tendon-derived and cartilage-derived extracellular matrices on adult mesenchymal stem cells. Stem Cell Res Ther 2017;8:133.

47. Rahmani Del Bakhshayesh A, Mostafavi E, Alizadeh E, et al. Fabrication of three-dimensional scaffolds based on nanobiomimetic collagen hybrid constructs for skin tissue engineering. ACS Omega 2018;3:8605-11.

48. Yao R, He J, Meng G, et al. Electrospun PCL/gelatin composite fibrous scaffolds: mechanical properties and cellular responses. J Biomater Sci Polym Ed 2016;27:824-38.

49. Hoshi K, Fujihara Y, Yamawaki T, et al. Biological aspects of tissue-engineered cartilage. Histochem Cell Biol 2018;149: 375-81.

50. Choi JR, Yong KW, Choi JY. Effects of mechanical loading on human mesenchymal stem cells for cartilage tissue engineering. J Cell Physiol 2018;233:1913-28.

51. Kobayashi J, Kikuchi A, Aoyagi T, et al. Cell sheet tissue engineering: cell sheet preparation, harvesting/manipulation, and transplantation. J Biomed Mater Res A 2019;107:95567.

52. Darling EM, Pritchett PE, Evans BA, et al. Mechanical properties and gene expression of chondrocytes on micropatterned substrates following dedifferentiation in monolayer. Cell Mol Bioeng 2009;2:395-404.

53. Mitani G, Sato M, Lee JI, et al. The properties of bioengineered chondrocyte sheets for cartilage regeneration. BMC Biotechnol 2009;9:17. 
54. Furukawa KS, Suenaga H, Toita K, et al. Rapid and largescale formation of chondrocyte aggregates by rotational culture. Cell Transplant 2003;12:475-9.

55. Gigout A, Buschmann MD, Jolicoeur M. Chondrocytes cultured in stirred suspension with serum-free medium containing pluronic- 68 aggregate and proliferate while maintaining their differentiated phenotype. Tissue Eng Part A 2009;15:2237-48.

56. Steinberg MS. Differential adhesion in morphogenesis: a modern view. Curr Opin Genet Dev 2007;17:281-6.

57. Athanasiou KA, Eswaramoorthy R, Hadidi P, et al. Self-organization and the self-assembling process in tissue engineering. Annu Rev Biomed Eng 2013;15:115-36.

58. Masuda K, Sah RL, Hejna MJ, et al. A novel two-step method for the formation of tissue-engineered cartilage by mature bovine chondrocytes: the alginate-recovered-chondrocyte (ARC) method. J Orthop Res 2003;21:139-48.

59. Huey DJ, Hu JC, Athanasiou KA. Chondrogenically tuned expansion enhances the cartilaginous matrix-forming capabilities of primary, adult, leporine chondrocytes. Cell Transplant 2013;22:331-40.

60. Alexander TH, Sage AB, Chen AC, et al. Insulin-like growth factor-I and growth differentiation factor-5 promote the formation of tissue-engineered human nasal septal cartilage. Tissue Eng Part C Methods 2010;16:1213-21.

61. Chang AA, Reuther MS, Briggs KK, et al. In vivo implantation of tissue-engineered human nasal septal neocartilage constructs: a pilot study. Otolaryngol Head Neck Surg 2012; 146:46-52.

62. Yanaga H, Imai K, Tanaka Y, et al. Two-stage transplantation of cell-engineered autologous auricular chondrocytes to regenerate chondrofat composite tissue: clinical application in regenerative surgery. Plast Reconstr Surg 2013;132:146777.

63. Hoshi K, Fujihara Y, Saijo H, et al. Three-dimensional changes of noses after transplantation of implant-type tissue-engineered cartilage for secondary correction of cleft lip-nose patients. Regen Ther 2017;7:72-9.

64. Fulco I, Miot S, Haug MD, et al. Engineered autologous cartilage tissue for nasal reconstruction after tumour resection: an observational first-in-human trial. Lancet 2014;384:33746.

65. Kundu J, Shim JH, Jang J, et al. An additive manufacturingbased PCL-alginate-chondrocyte bioprinted scaffold for cartilage tissue engineering. J Tissue Eng Regen Med 2015; 9:1286-97.

66. Xu Y, Fan F, Kang N, et al. Tissue engineering of human nasal alar cartilage precisely by using three-dimensional print- ing. Plast Reconstr Surg 2015;135:451-8.

67. Apelgren P, Amoroso M, Lindahl A, et al. Chondrocytes and stem cells in 3D-bioprinted structures create human cartilage in vivo. PLoS One 2017;12:e0189428.

68. Schwarz S, Elsaesser AF, Koerber L, et al. Processed xenogenic cartilage as innovative biomatrix for cartilage tissue engineering: effects on chondrocyte differentiation and function. J Tissue Eng Regen Med 2015;9:E239-51.

69. Akbari P, Waldman SD, Propst EJ, et al. Generating mechanically stable, pediatric, and scaffold-free nasal cartilage constructs in vitro. Tissue Eng Part C Methods 2016;22:1077-84.

70. Rodriguez A, Cao YL, Ibarra C, et al. Characteristics of cartilage engineered from human pediatric auricular cartilage. Plast Reconstr Surg 1999;103:1111-9.

71. Park SS, Jin HR, Chi DH, et al. Characteristics of tissue-engineered cartilage from human auricular chondrocytes. Biomaterials 2004;25:2363-9.

72. Kamil SH, Vacanti MP, Vacanti CA, et al. Microtia chondrocytes as a donor source for tissue-engineered cartilage. Laryngoscope 2004;114:2187-90.

73. Nakao H, Jacquet RD, Shasti M, et al. Long-term comparison between human normal conchal and microtia chondrocytes regenerated by tissue engineering on nanofiber polyglycolic acid scaffolds. Plast Reconstr Surg 2017;139:911e921e.

74. Yanaga H, Imai K, Fujimoto T, et al. Generating ears from cultured autologous auricular chondrocytes by using twostage implantation in treatment of microtia. Plast Reconstr Surg 2009; 124:817-25.

75. Yanaga H, Imai K, Koga M, et al. Cell-engineered human elastic chondrocytes regenerate natural scaffold in vitro and neocartilage with neoperichondrium in the human body post-transplantation. Tissue Eng Part A 2012;18:2020-9.

76. Zhang L, He A, Yin Z, et al. Regeneration of human-earshaped cartilage by co-culturing human microtia chondrocytes with BMSCs. Biomaterials 2014;35:4878-87.

77. Cohen BP, Bernstein JL, Morrison KA, et al. Tissue engineering the human auricle by auricular chondrocyte-mesenchymal stem cell co-implantation. PLoS One 2018;13: e0202356.

78. Zhou G, Jiang H, Yin Z, et al. In vitro regeneration of patientspecific ear-shaped cartilage and its first clinical application for auricular reconstruction. EBioMedicine 2018;28:287302.

79. Bernstein JL, Cohen BP, Lin A, et al. Tissue engineering auricular cartilage using late passage human auricular chondrocytes. Ann Plast Surg 2018;80(4 Suppl 4):S168-73.

80. Nayyer L, Patel KH, Esmaeili A, et al. Tissue engineering: 
revolution and challenge in auricular cartilage reconstruction. Plast Reconstr Surg 2012;129:1123-37.

81. Shieh SJ, Terada S, Vacanti JP. Tissue engineering auricular reconstruction: in vitro and in vivo studies. Biomaterials 2004; 25:1545-57.

82. Mendes LF, Katagiri H, Tam WL, et al. Advancing osteochondral tissue engineering: bone morphogenetic protein, transforming growth factor, and fibroblast growth factor signaling drive ordered differentiation of periosteal cells resulting in s cartilage and bone formation in vivo. Stem Cell Res Ther 2018;9:42.

83. Wang Y, Kim UJ, Blasioli DJ, et al. In vitro cartilage tissue engineering with $3 \mathrm{D}$ porous aqueous-derived silk scaffolds and mesenchymal stem cells. Biomaterials 2005;26:708294.

84. Tay AG, Farhadi J, Suetterlin R, et al. Cell yield, proliferation, and postexpansion differentiation capacity of human ear, nasal, and rib chondrocytes. Tissue Eng 2004;10:762-70.
85. Hicks DL, Sage AB, Shelton E, et al Effect of bone morphogenetic proteins 2 and 7 on septal chondrocytes in alginate. Otolaryngol Head Neck Surg 2007;136:373-9.

86. Kamil SH, Kojima K, Vacanti MP, et al. Tissue engineered cartilage: utilization of autologous serum and serum-free media for chondrocyte culture. Int J Pediatr Otorhinolaryngol 2007;71:71-5.

87. Yang D, Xiao J, Wang B, et al. The immune reaction and degradation fate of scaffold in cartilage/bone tissue engineering. Mater Sci Eng C Mater Biol Appl 2019;104:109927.

88. Julier Z, Park AJ, Briquez PS, et al. Promoting tissue regeneration by modulating the immune system. Acta Biomater 2017;53:13-28.

89. Zhang X, Wu Y, Pan Z, et al. The effects of lactate and acid on articular chondrocytes function: implications for polymeric cartilage scaffold design. Acta Biomater 2016;42:32940. 